Natural Hazards and Earth System Sciences (2003) 3: 249-253

(C) European Geosciences Union 2003

Natural Hazards and Earth System Sciences

\title{
GPS detection of ionospheric perturbation before the 13 February 2001, El Salvador earthquake
}

\author{
V. V. Plotkin \\ Institute of Geophysics, Koptyug Str. 3, 630090 Novosibirsk, Russia \\ Received: 13 May 2002 - Revised: 30 July 2002 - Accepted: 19 August 2002
}

\begin{abstract}
A large earthquake of $M 6.6$ occurred on 13 February 2001 at 14:22:05 UT in El Salvador. We detected ionospheric perturbation before this earthquake using GPS data received from CORS network. Systematic decreases of ionospheric total electron content during two days before the earthquake onset were observed at set of stations near the earthquake location and probably in region of about $1000 \mathrm{~km}$ from epicenter. This result is consistent with that of investigators, which studied these phenomena with several observational techniques. However it is possible, that such TEC changes are simultaneously accompanied by changes due to solar wind parameters and $K_{p}$-index.
\end{abstract}

\section{Introduction}

Total electron content (TEC) in ionosphere has been widely studied using the Global Positioning System (GPS) to understand mechanisms of ionospheric perturbations. Global (e.g. Ho et al., 1996; Lu et al., 1998) and various local (e.g. Calais and Minster, 1995, 1996; Afraimovich et al., 1998; Calais et al., 1998) TEC perturbations in the ionosphere have been investigated in recent years.

Ionospheric disturbances before great earthquakes have been studied with several observational techniques (e.g. Ondoh, 1998; Pulinets, 1998; Zaslavski et al., 1998; Liu et al., 2000). However, measurements from single stations or single orbiting satellites carrying ionospheric sensors cannot monitor the response of the ionosphere to every large event because of the lack of instantaneous global coverage. Understanding the coupling processes between the lithosphere and the ionosphere requires a continuously operating global monitoring system, such as GPS network. We demonstrate in this paper the capabilities of the GPS receivers to detect the ionospheric TEC perturbation before the 13 February 2001, El Salvador earthquake.

Correspondence to: V. V. Plotkin (plotkin@uiggm.nsc.ru)

\section{Data and method}

A large earthquake of M6.6 occurred on 13 February 2001 at 14:22:05 UT in El Salvador $\left(13.64^{\circ} \mathrm{N}, 271.06^{\circ} \mathrm{E}\right.$, Depth $13.0 \mathrm{~km}$, see http://neic.usgs.gov. We obtained GPS data (see http://www.ngs.noaa.gov/CORS/ by FTP from the CORS network, that provides GPS carrier phase and code range measurements. In this study, we investigated TEC perturbation in the ionosphere using six GPS receivers from CORS network. Figure 1 shows geographic locations of these stations. The four GPS stations namely ESTI, MANA, SLOR and TEGU are distributed near the earthquake epicenter. We used also the GPS receivers at the two north stations namely KYW1 and HTV1 for comparison. The sampling rate of each GPS receiver is $30 \mathrm{~s}$.

A method of reconstructing TEC variations from GPS data was detailed in publications (e.g. Hofmann-Wellenhof et al., 1992; Calais and Minster, 1995). The vertically corrected TEC data were obtained from the line of sight GPS observations at different elevation angles $\theta$ using a simplified obliquity factor namely $\sin \theta$. Data from elevation angles $\theta$ lower than $60^{\circ}$ are not included to reduce possible errors in the estimation of TEC.

Phase measurements in the GPS can be made with a high degree of accuracy corresponding to the error of TEC determination of at least $10^{13} \mathrm{~m}^{-2}$ when averaged on a $30-\mathrm{s}$ time interval, with some uncertainly of the initial value of TEC (Afraimovich et al., 1998). Group delay measurements give an opportunity to determine the absolute value of TEC, but with an error worse than $10^{15} \mathrm{~m}^{-2}$ when also averaged on a 30 -s time interval. In order to obtain an absolute and precise estimate of the TEC a linear combination of the phase and group delays measurements can be used (Calais et al., 1998). In this paper we are interested in the absolute value of TEC, but preliminary we used only the group delay measurements. We pre-processed these data in order to exclude small signals. The estimations of TEC from all observable satellites during period from 11-13 February 2001 are shown in three top panels of Fig. 2 (the locations of GPS receivers are indi- 


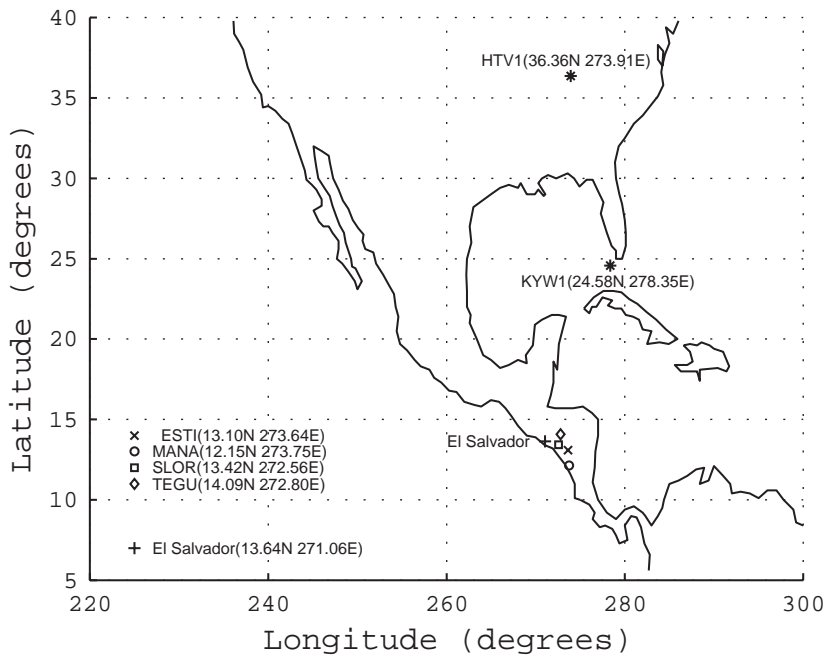

Fig. 1. Geographic locations of earthquake epicenter (+) and observation stations.

cated in each panel). The simultaneous crossing of radio ray paths from different GPS satellites is the reason that the TEC in Fig. 2 have more than one values at the same time.

In the bottom panel of Fig. 2 is shown the three-hour $K_{p}$ index. We obtained these data from U.S. National Geophysical Data Center by FTP. The low or moderate geomagnetic activity during period from 11-13 February 2001 is associated with the rather quiet time.

\section{Results and discussion}

The TEC time-series in Fig. 2 are dominated by highamplitude variations with periods of several hours related to the daily solar cycle and to the displacements of the satellites. Figure 2 shows also several variations at higher frequencies. These variations do not allow with the necessary accuracy to compare the data during several days. Therefore in order to improve the accuracy of the TEC estimations we averaged raw TEC time-series on a time intervals when elevation angles $\theta$ are larger than $60^{\circ}$. We detrended also raw TEC time-series and removed a fourth-order polynomial in order to calculate root-mean-square values (rms) for these TEC time-series.

Further we selected the TEC estimations received which had small day-to-day variability to exclude several perturbations concerning only given satellite-receiver pair. Thus we used the TEC data derived from six satellites PRN06, PRN17, PRN19, PRN21, PRN22 and PRN27 at set of stations near the earthquake epicenter. At the KYW1 station we used the TEC data derived from nine satellites PRN01, PRN02, PRN06, PRN17, PRN19, PRN21, PRN22, PRN26 and PRN27. At last at the HTV1 station we used the TEC data derived from eleven satellites PRN01, PRN02, PRN10, PRN14, PRN17, PRN19, PRN21, PRN22, PRN23, PRN25 and PRN26. All average TEC and their rms values during period from 11-13 February 2001 are shown in three panels of Fig. 3 (the locations of GPS receivers are indicated in each panel).

These TEC data are already more suitable to compare their values per different days. It is easy to look after the repeatability of TEC data within three days on each panel. Further we used the differential TEC technique as in paper (Hernandez-Pajares et al., 1997). Subtraction of these TEC values $\left((\mathrm{TEC})_{i}-(\mathrm{TEC})_{i+1}\right)$ for given and next days gives the difference estimations of TEC. The received differences of the TEC are shown in Fig. 4. These TEC differences are various at set of stations near the earthquake epicenter and at the HTV1 station. However these TEC differences are slightly similar in region near the earthquake epicenter and at the KYW1 station. Systematic decreases of the ionospheric TEC during two days before the earthquake onset were observed at set of stations near the earthquake epicenter and probably at KYW1 station.

This result is consistent with that of earlier investigators (e.g. Ondoh, 1998; Pulinets, 1998; Zaslavski et al., 1998). A great earthquake of M7.8 occurred on 12 July 1993 in northern Japan. Systematic decreases of the ionospheric F2-layer critical frequency below its monthly median from 3 days before this earthquake onset to 3 days after it were observed (Ondoh, 1998). Local geomagnetic activities were quiet or moderate with no geomagnetic storm from 5-16 July 1993. Therefore the ionospheric disturbances observed were independent of solar-terrestrial events.

Stable modifications of the equatorial ionosphere during few days before the 15 August 1963 earthquake of $M 7.75\left(13.8^{\circ} \mathrm{S}, 69.3^{\circ} \mathrm{W}\right)$ and similarly before the 20 March 1979 earthquake of $M 5.3\left(7.56^{\circ} \mathrm{N}, 126.6^{\circ} \mathrm{E}\right)$ were also observed (Depueva and Rotanova, 2000). The decreases of the ionospheric F2-layer critical frequency in region of about $1000 \mathrm{~km}$ from epicenter were occurred. This result is consistent with our estimation if to take into account distance from epicenter up to KYW1 station.

The TEC value significantly decreases 1,3 and 4 days also before the 20 September 1999, Chi-Chi earthquake of $M 7.7$ (Liu et al., 2001). In our case before El Salvador earthquake of M6.6 the TEC value decreases less appreciablly. It is visible only due to used differential TEC technology. If we compare further changes of TEC before these earthquakes, we can see in both cases some similarity of TEC and $K_{p^{-}}$ index changes. Figure 5 displays variations (normalized on a maximum) of the midday (12:00 LT) values of TEC and $K_{p}$-index within some days during El Salvador and Chi-Chi earthquakes. The TEC data from ESTI station during El Salvador earthquake and the TEC data from Fig. 2 (Liu et al., 2001) during Chi-Chi earthquake are used. We obtained the $K_{p}$-index data from U.S. National Geophysical Data Center by FTP. The equatorward motions and significant TEC decreases of the equatorial anomaly crest during Chi-Chi earthquake suggest that an upward electric field near the epicenter and/or the equatorward neutral wind in the ionosphere play important roles (Liu et al., 2001). At the same time changes of $K_{p}$-index can be connected to changes of solar wind parameters. Therefore it is possible, that the changes of solar 

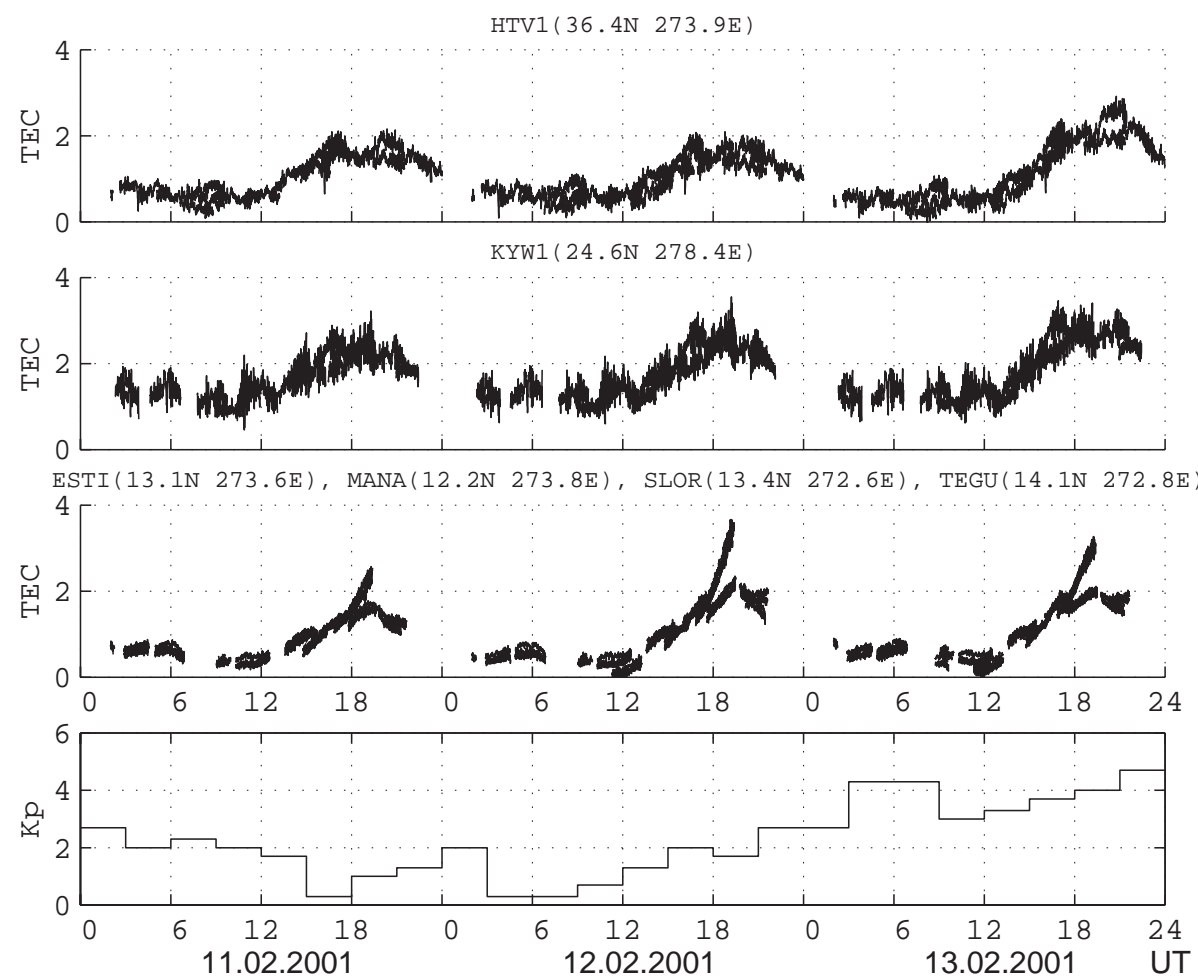

Fig. 2. Variations of TEC from all observable satellites (three top panels, in unit $10^{16} \mathrm{~m}^{-2}$ ) and the three-hour $K_{p}$ index (the bottom panel) during period from 11-13 February 2001.
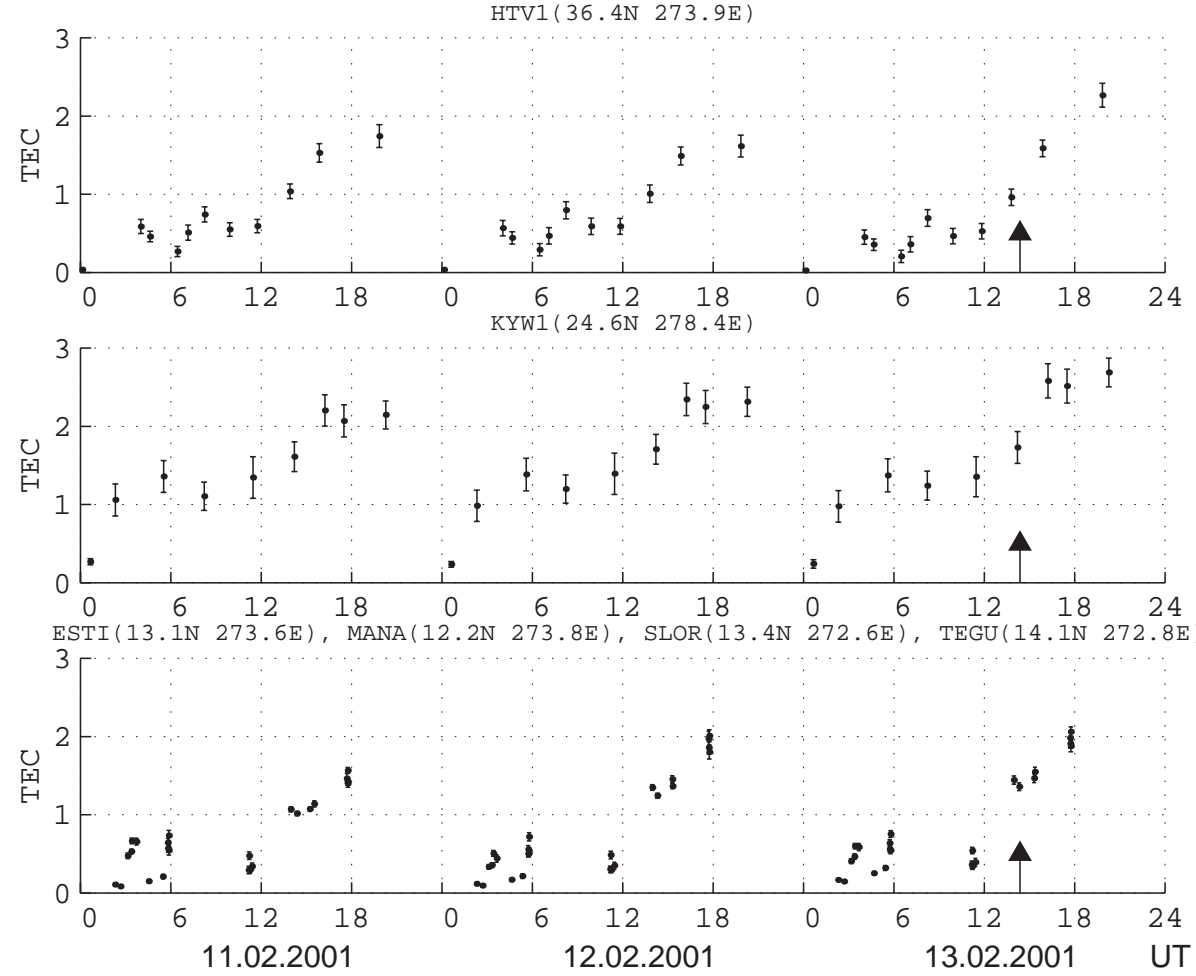

Fig. 3. Selected average TEC and their rms values (in unit $10^{16} \mathrm{~m}^{-2}$ ) during period from $11-13$ February 2001 . The earthquake onset is shown on each panel by arrows. 

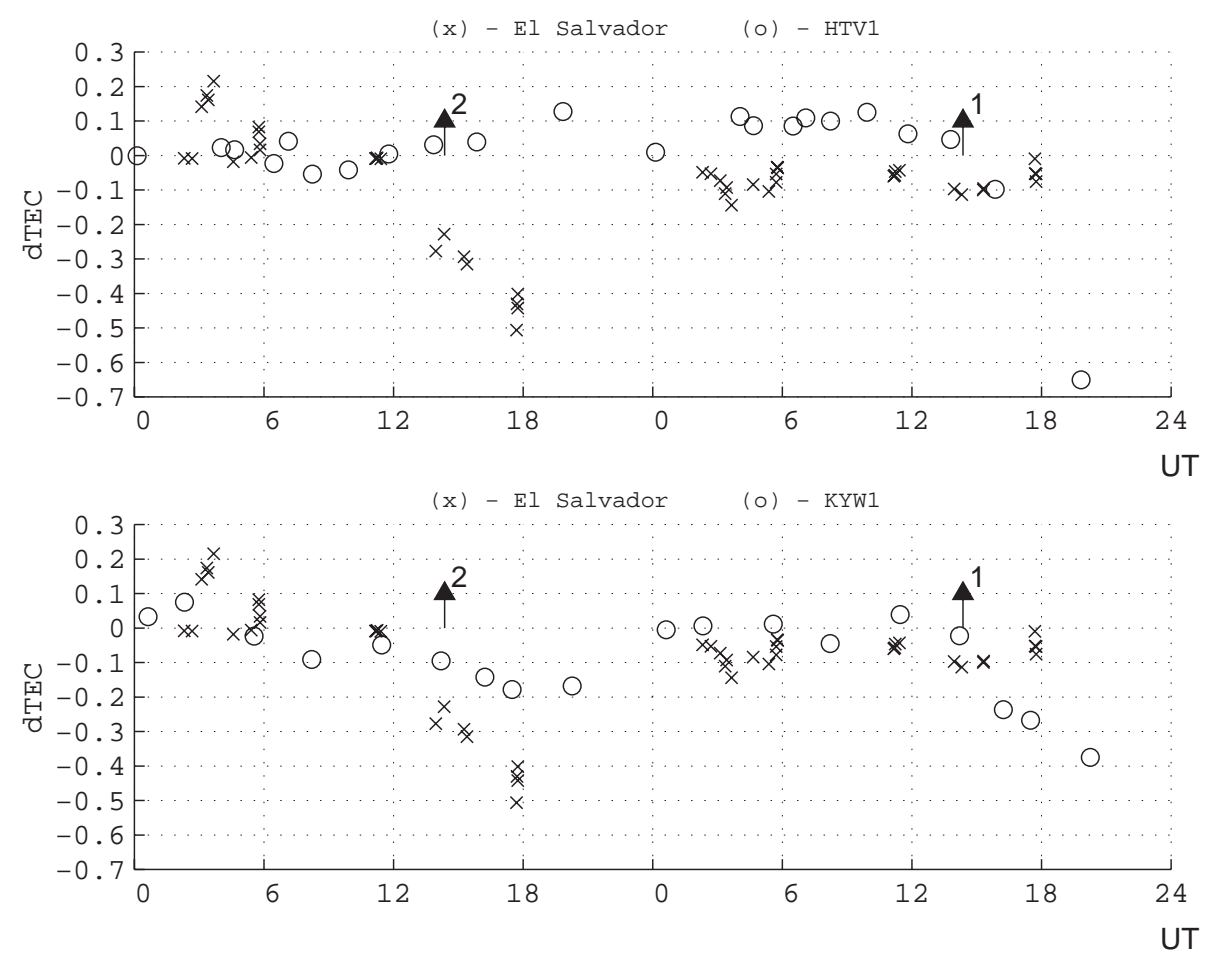

Fig. 4. Comparison of TEC differences (in unit $10^{16} \mathrm{~m}^{-2}$ ) at set of stations near the earthquake epicenter (x) with ones (o) at the HTV1 (top) and the KYW1 (bottom) stations. The day numbers before the earthquake onset are shown near arrows.
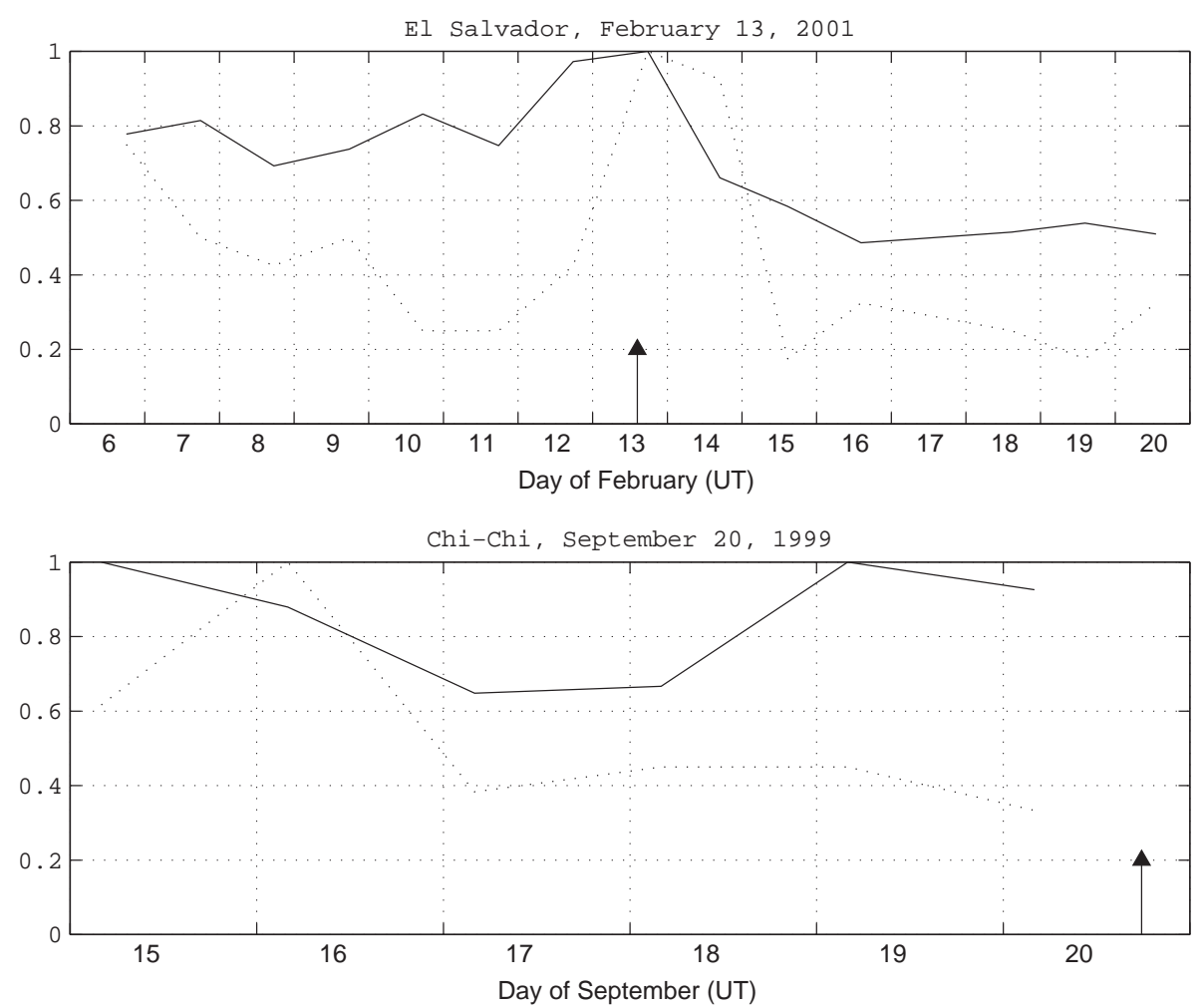

Fig. 5. Normalized on a maximum variations of the midday (12:00 LT) values of TEC (solid curves) and $K_{p}$-index (dots) within some days during El Salvador (top) and Chi-Chi (bottom) earthquakes. The earthquake onset is shown on each panel by arrows. 
wind parameters had also an effect for TEC changes in both cases. To check up this circumstance, the investigations of other events are necessary.

Other possible mechanisms of the ionospheric disturbances associated with the imminent earthquake are again discussed. Electromagnetic effects are studied by many authors (e.g. Kuznetsov et al., 1995; Kim and Hegai, 1997; Sorokin et al., 2001). The formation of plasma perturbation in the upper ionosphere (Kim and Hegai, 1997) and a injection of radioactive substances and charged aerosols into the atmosphere (Sorokin et al., 2001) near the epicenter of an imminent earthquake have been studied. New detailed investigations of ionospheric disturbances before large earthquakes are necessary for final understanding of mechanisms these phenomena.

\section{Conclusion}

We detected the ionospheric TEC perturbation before the 13 February 2001, El Salvador earthquake of M6.6 using GPS data. Systematic decreases of the ionospheric TEC during two days before the earthquake onset were observed at set of stations near the earthquake location and probably in region of about $1000 \mathrm{~km}$ from epicenter. This result is consistent with that of investigators, which studied these phenomena with several observational techniques. However it is possible, that such TEC changes are simultaneously accompanied by changes due to solar wind parameters and $K_{p^{-}}$ index. Therefore investigations with GPS of these phenomena, especially in regions with dense permanent GPS coverage, are necessary for studying coupling processes between the lithosphere and the ionosphere and for final understanding of mechanisms these phenomena.

Acknowledgements. The author wish to thank U.S. National Earthquake Information Center, U.S. National Geodetic Survey and U.S. National Geophysical Data Center for providing geophysical data.

\section{References}

Afraimovich, E. L., Palamartchouk, K. S., Perevalova, N. P., Chernukhov, V. V., Lukhnev, A. V., and Zalutsky, V. T.: Ionospheric effects of the solar eclipse of 9 March 1997, as deduced from GPS data, Geophys. Res. Lett., 25, 465-468, 1998.

Calais, E. and Minster, J. B.: GPS detection of ionospheric perturbations following the 17 January 1994, Northridge earthquake,
Geophys. Res. Lett., 22, 1045-1048, 1995.

Calais, E. and Minster, J. B.: GPS detection of ionospheric perturbations following a Space Shuttle ascent, Geophys. Res. Lett., 23, 1897-1900, 1996.

Calais, E., Minster, J. B., Hofton, M. A., and Hedlin, M. A. H.: Ionospheric signature of surface mine blasts from Global Positioning System measurements, Geophys. J. Inter., 132, 191-202, 1998.

Depueva, A. H. and Rotanova, N. M.: Modification of the ionosphere in the lower and equatorial latitudes before the earthquakes (in Russian), Geomagn. Aeronom., 40, 50-54, 2000.

Hernandez-Pajares, M., Juan, J. M., and Sanz, J.: High resolution TEC monitoring method using permanent ground GPS receivers, Geophys. Res. Lett., 24, 1643-1646, 1997.

Ho, C. M., Mannucci, A. J., Lindqwister, U. J., Pi, X., and Tsurutani, B. T.: Global ionosphere perturbations monitored by the worldwide GPS network, Geophys. Res. Lett., 23, 3219-3222, 1996.

Hofmann-Wellenhof, B., Lichtenegger, H., and Collins, J.: Global Positioning System: theory and practice, 326 pp., SpringerVerlag Wien, New York, 1992.

Kim, V. P. and Hegai, V. V.: On possible changes in the midlatitude upper ionosphere before strong earthquake, J. Earthquake Predict., Res., 6, 275-280, 1997.

Kuznetsov, V. V., Plotkin, V. V., Izraileva, N. I., and Nesterova, I. I.: The investigation of electromagnetic interactions between regions surrounding the Earth, J. Atmos. Terr. Phys., 57, 16391660, 1995.

Liu, J. Y., Chen, Y. I., Pulinets, S. A., Tsai, Y. B., and Chuo, Y. J.: Seismo-ionospheric signatures prior to $M \geq 6.0$ Taiwan earthquakes, Geophys. Res. Lett., 27, 3113-3116, 2000.

Liu, J. Y., Chen, Y. I., Chuo, Y. J., and Tsai, H. F.: Variations of ionospheric total electron content during Chi-Chi earthquake, Geophys. Res. Lett., 28, 1383-1386, 2001.

Lu, G., Pi., X., Richmond, A. D., and Roble, R. G.: Variations of total electron content during geomagnetic disturbances, Geophys. Res. Lett., 25, 253-256, 1998.

Ondoh, T.: Ionospheric disturbances associated with great earthquake of Hokkaido southwest coast, Japan of 12 July 1993, Phys. Earth and Planet. Inter., 105, 261-269, 1998.

Pulinets, S. A.: Strong earthquake prediction possibility with the help of topside sounding from satellites, Adv. Space Res., 21 , 455-458, 1998.

Sorokin, V. M., Chmyrev, V. M., and Yaschenko, A. K.: Electrodynamic model of the lower atmosphere and the ionosphere coupling, J. Atmos. Sol. Terr. Phys., 63, 1681-1691, 2001.

Zaslavski, Y., Parrot, M., and Blanc, E.: Analysis of TEC measurements above active seismic regions, Phys. Earth and Planet. Inter., 105, 219-228, 1998. 